\section{Planejamento e gestão: para além da comunicação}

Planning and management: going beyond communication

\section{Jairnilson Silva Paim ${ }^{3}$}

Este texto de Rivera e Artmann merece ser saudado pela oportunidade da sua divulgação, pelos objetivos explicitados e pelas questões que suscita. $\mathrm{O}$ empenho de atualizar a sistematização de algumas tendências teórico-metodológicas do Planejamento e Gestão em Saúde (P\&GS) no Brasil, adotando uma perspectiva pluralista de conceber as distintas correntes de pensamento e apontando possíveis espaços de diálogo entre as mesmas, revela uma postura amadurecida e generosa, fundamental para um campo em construção como é a Saúde Coletiva. A exploração das potencialidades do agir comunicativo e de outros paradigmas no âmbito do $\mathrm{P} \& \mathrm{GS}$ confere ao artigo um caráter inovador, ao tempo em que estimula reflexões e crítica.

$\mathrm{O}$ artigo aponta para evoluções no interior das "escolas", como é o caso do grupo da USP, ao contemplar as questões do cuidado e da subjetividade; ou o da Unicamp, ao desenvolver a proposta do acolhimento. Do mesmo modo, assinala os desdobramentos teórico-metodológicos do grupo da ENSP quando se abre para a "gestão pela escuta”, para as "organizações que aprendem" e para o desenvolvimento de capacidades de liderança. Refere-se aos estudos da corrente da Vigilância da Saúde, voltados para a mudança do modelo de atenção.

Se é verdade que o planejamento possa ser utilizado nessa mudança, isto não parece suficiente para caracterizar uma corrente de P\&GS. Na realidade, modelos de atenção têm mais a ver com modos tecnológicos de intervenção, ou seja, combinação de tecnologias estruturadas para responder a necessidades e problemas de saúde ${ }^{1}$. Dizem respeito ao "conteúdo" das ações, ou seja, à dimensão técnica do cuidado e da intervenção em saúde. Analiticamente, diferem do "continente" - sistema de serviços e organizações de saúde -, não obstante as suas relações com os mesmos.

Assim, "a proposta de Sistemas de Microrregionalização Solidária”, por exemplo, ilustra uma atuação sobre o "continente", não uma corrente de P\&GS. Aliás, desde as primeiras reflexões teóricas sobre distritos sanitários, já era formulada uma diferenciação entre modelo organizacionalgerencial e modelo de atenção. E foi justamente baseando-se na teoria do processo de trabalho que um projeto de redefinição de práticas de saúde, rearticulando a demanda espontânea, a oferta organizada e os programas especiais, resultou na proposta de Vigilância da Saúde. Do mesmo modo que o grupo do Lappis, a "escola" da Vigilância da Saúde, busca modos de efetivar a diretriz de integralidade.

Tecnologias utilizadas na atenção não podem ser confundidas com planejamento e gestão de redes e serviços de saúde. É claro que o P\&GS pode representar uma mediação entre as políticas públicas e o cuidado ou a intervenção em saúde, facilitando a sua concretização e levando o planejamento para a intimidade das práticas de saúde. Mesmo quando a Vigilância da Saúde é parcialmente incorporada enquanto política ${ }^{2}$, não parece caracterizar uma corrente de P\&GS.

Se for correto pensar que as propostas acima comentadas referem-se mais a modelos de atenção do que a enfoques teórico-metodológicos de P\&GS, o que efetivamente há de novo nesta área multidisciplinar? Embora uma recuperação mais exaustiva do estado da arte no Brasil se faça necessária, certamente que o artigo indica várias propostas inovadoras. No caso do grupo baiano, talvez uma característica a ser mencionada resida no esforço de articular a investigação e a intervenção em $P \& G S$ em organizações públicas de saúde municipais, estaduais e federais ${ }^{3-6}$.

$\mathrm{O}$ artigo pode, ainda, estimular uma reflexão acerca dos fundamentos do P\&GS, indagando sobre seus saberes e práticas a partir de autores que contribuíram para as teorias da ação e, especificamente, para o planejamento e a gestão de organizações. Este percurso poderia fornecer algumas pistas para que, ao lado dos elementos abstrato-formais das teorias, dos métodos e das técnicas, sejam valorizados, igualmente, os elementos histórico-concretos ${ }^{7}$. Não deve ser por acaso que textos recentes sobre teorias das organizações estejam revendo esses autores para a renovação da gestão ${ }^{8,9}$. Habermas representa uma fonte profícua para o P\&GS, seja pela sua contribuição à reconstrução do materialismo históri$\mathrm{co}^{10}$, seja pela crítica à teoria da ação racional, seja pelas potencialidades da teoria do agir comunicativo para apoiar o entendimento e o consenso nos processos políticos no âmbito da saúde. Embora os autores reconheçam a necessidade de planejar em situações de conflito, defen-

\footnotetext{
${ }^{3}$ Instituto de Saúde Coletiva, Universidade Federal da Bahia. jairnil@ufba.br
} 
dem a necessidade de "fortalecer a capacidade de escuta do outro e de interação e negociação". A dúvida é se o agir comunicativo "representa uma alternativa ao agir estratégico".

Habermas ${ }^{11}$ destacou que a ação teleológica pode ser dirigida ao mundo objetivo (ação instrumental), como a lógica dos insumos na programação ou ao mundo social, quando se busca o êxito (ação estratégica). Já a ação comunicativa contempla o mundo subjetivo a partir das vivências dos interlocutores. Ainda que o filósofo tenha desenvolvido a teoria da ação comunicativa, não parece ter descartado os outros tipos de ação. Se não houver sérios equívocos nessa leitura, quando e como o planejamento e a gestão dispensariam a realização de um propósito (ação teleológi$\mathrm{ca})$ ? Como atuariam gestores e planejadores em situações com assimetria de poder, distantes de uma "comunidade ideal de diálogo"? Como em tais circunstâncias o agir comunicativo poderia ser uma alternativa ao pensamento estratégico?

Numa entrevista, perguntaram a Jürgen Habermas como ele via a aplicação de sua teoria nos países da América Latina. Coerente com o seu agir comunicativo, respondeu com toda sinceridade: "não sei, quando a elaborei estava pensando na Europa e na Alemanha". Não deve ser por outra razão que Mario Testa, um dos pensadores do nosso campo que também estudou Habermas, questione o agir comunicativo em determinados contextos ${ }^{12}$.

Isto não significa valorizar o sistema em detrimento do mundo da vida, nem subordinar a comunicação à ação instrumental ou estratégica. Pelo contrário, ao tempo em que ressalta o simbólico, a linguagem e o imaginário, sobretudo nos seus trabalhos mais recentes ${ }^{13,14}$, reforça a necessidade de contextualização e de análises concretas de situações concretas. Se é possível acionar o agir comunicativo numa "equipe-interação"15, ou em seminários de doutorado na universidade, há dúvidas quanto a sua pertinência numa política de regionalização quando gestores deixam de cumprir os pactos acordados ${ }^{16}$ ou num hospital de emergência em que profissionais de saúde protelam o atendimento com omissão de socorro. Nestes casos, o tempo consumido na construção do consenso e na busca de entendimento pode custar a vida de outras pessoas. Portanto, a análise situacional, a planificação estratégico-situacional, a programação, o pensamento estratégico e o planejamento comunicativo oferecem, numa perspectiva pluralista, várias possibilidades de utilização na dependência de cada situação concreta.
Daí a pertinência de contextualizarmos nossas categorias de análise, teorias e propostas de ação, articulando os elementos abstrato-formais e histórico-concretos, sempre abertos a novos paradigmas. Para além da comunicação, persiste o desafio de triangular a produção teóricometodológica, a experiência técnico-institucional e a militância sociopolítica.

\section{Referências}

1. Paim JS. Modelos de Atenção à Saúde no Brasil. In: Giovanella L, organizadora. Políticas e Sistema de Saúde no Brasil. Rio de Janeiro: Fiocruz; 2008. p. 547-573.

2. Brasil. Ministério da Saúde. Portaria $n^{\circ} 3.252$ de 22 de dezembro de 2009. Aprova as diretrizes para execução e financiamento das ações de Vigilância em Saúde. Diário Oficial da União 2009; 23 dez.

3. Teixeira CF, organizador. Planejamento em Saúde: conceitos, métodos e experiências. Salvador: EDUFBA. No prelo 2010 .

4. Coelho TCB, Paim JS Processo decisório e práticas de gestão: dirigindo a Secretaria da Saúde do Estado da Bahia, Brasil. Cad Saude Publica 2005; 21(5):1373-1382.

5. Souto AC. O processo de gestão na Agência Nacional de Vigilância Sanitária - Anvisa [tese]. Salvador (BA): Instituto de Saúde Coletiva, Universidade Federal da Bahia; 2007.

6. Vilasbôas ALQ, Paim JS. Práticas de planejamento e implantação de políticas no âmbito municipal. Cad Saude Publica 2008; 24(6):1239-1250.

7. Giordani JA. Planificación, Ideología y Estado: El caso de Venezuela. Valencia: Vadel Hermanos Editores; 1986.

8. Clegg SR, Hardy C, Nord WR. Handbook de Estudos Organizacionais. Reflexões e Novas Direções. Vol. 2. São Paulo: Atlas; 2001.

9. Rouleau L. Théorie des Organisations: classiques, contemporains et avant-garde. Montreal : HEC-Université de Montreal ; 2005.

10. Habermas J. La reconstrucción del materialismo histórico. Madrid: Taurus Ediciones; 1986.

11. Habermas J. Relaciones con el mundo y aspectos de a racionalidad de la acción en cuatro conceptos sociológicos de acción. In: Habermas J. Teoría de la acción comunicativa I. Madrid: Taurus; 1987. p. 110-146.

12. Memoria e Historia: charla de Mario Testa y Jairnilson Silva Paim. Salud Colectiva. No prelo 2010.

13. Spinelli H, Testa M. Del Diagrama de Venn al Nudo Borromeo. Desarrollo de la Planificación en América Latina. Salud Colectiva 2005; 1(3):323-335.

14. Testa M. Decidir en Salud. Quién? Cómo? Y Por qué? Salud Colectiva 2007; 3(3):247-257.

15. Peduzzi M. Equipe multiprofissional de saúde: a interface entre trabalho e interação [tese]. Campinas (SP): Faculdade de Ciências Médicas, Universidade Estadual de Campinas; 1998.

16. Lopes CMN. Regionalização em saúde: o caso de uma microrregião no Ceará (1998-2002 e 2007-2009) [tese]. Salvador (BA): Instituto de Saúde Coletiva, Universidade Federal da Bahia; 2010. 